\title{
Olefin-surface interactions: a key activity parameter in silica-supported
}

\section{olefin metathesis catalysts}

Zachariah J. Berkson, ${ }^{a}$ Moritz Bernhardt,${ }^{a}$ Simon Schlapansky, ${ }^{a}$ Mathis J. Benedikter, ${ }^{b}$ Michael R. Buchmeiser, ${ }^{b}$ Gregory A. Price, ${ }^{c}$ Glenn J. Sunley, ${ }^{c}$ Christophe Copéret ${ }^{a *}$

${ }^{a}$ Department of Chemistry and Applied Bioscience, ETH Zürich, Vladimir-Prelog-Weg 2, 8093 Zürich, Switzerland.

${ }^{\mathrm{b}}$ Institute of Polymer Chemistry, Universität Stuttgart, Pfaffenwaldring 55, 70569 Stuttgart, Germany

${ }^{\mathrm{c}}$ Applied Sciences, bp Innovation \& Engineering, BP plc, Saltend, Hull, HU12 8DS, UK

*Corresponding author. Email: ccoperet@ethz.ch

\begin{abstract}
Molecularly defined and classical heterogenous Mo-based metathesis catalysts are shown to display distinct and unexpected reactivity patterns for the metathesis of long-chain $\alpha$-olefins at low temperatures $\left(<100^{\circ} \mathrm{C}\right)$. Namely, catalysts based on supported Mo oxo species, whether prepared via wet impregnation or surface organometallic chemistry (SOMC), exhibit strong activity dependencies on the $\alpha$-olefin chain length, with slower reaction rates for longer substrate chain lengths. In contrast, molecular and supported Mo alkylidenes are highly active and do not display such dramatic dependence on chain length. State-of-the-art 2D solid-state NMR analyses of post-metathesis catalysts, complemented by FTIR and molecular dynamics calculations, evidence that the activity decrease observed for supported Mo oxo catalysts relates to the strong adsorption of internal olefin metathesis products due to interactions with surface $\mathrm{Si}-\mathrm{OH}$ groups. Overall, this study shows that in addition to the nature and the number of active sites, the metathesis rates and overall catalytic performance depend on product desorption, even in the liquid phase with non-polar substrates. This study further highlights the role of support and active site composition and dynamics on activity as well as the need to consider adsorption in catalyst design.
\end{abstract}




\section{Introduction}

Olefin metathesis is a key technology for the formation of $\mathrm{C}=\mathrm{C}$ bonds by rearrangement of alkylidene fragments among olefins. ${ }^{1}$ Decades of research have yielded highly active and selective olefin metathesis catalysts based on molecular Mo-, W-, and Ru-alkylidenes that are highly active at low temperatures (e.g. room temperature to $100{ }^{\circ} \mathrm{C}$ ) and tolerant to functional groups in many instances, enabling broad applications in organic and polymer syntheses (Figure 1a). ${ }^{2-6}$ By comparison, heterogeneous olefin metathesis catalysts, mostly based on supported Mo or W oxides, are industrially used for the upgrading of light olefins ${ }^{7}$ but require high-temperature activation and/or reaction conditions $\left(>150{ }^{\circ} \mathrm{C}\right.$ and even $400{ }^{\circ} \mathrm{C}$ for W-based catalysts). ${ }^{8}$ They are composed of ill-defined surface structures with low ( $\left.<5 \%\right)$ quantities of active sites, and are proposed to involve complex initiation processes at high temperatures, involving for instance surface $\mathrm{OH}$ groups. ${ }^{9-11}$ These shortcomings have limited their broader adoption.

Although the nature of the active sites has remained elusive, it is now accepted that the active sites correspond to high-valent alkylidenes as for their molecular analogues, generated in situ from isolated, high

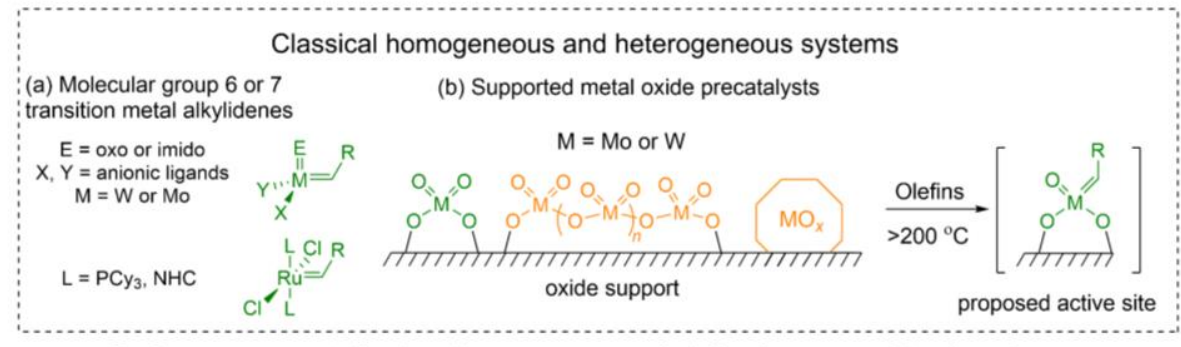

Surface organometallic chemistry routes to well-defined supported (pre)catalysts

(c) Isolated metal oxo sites

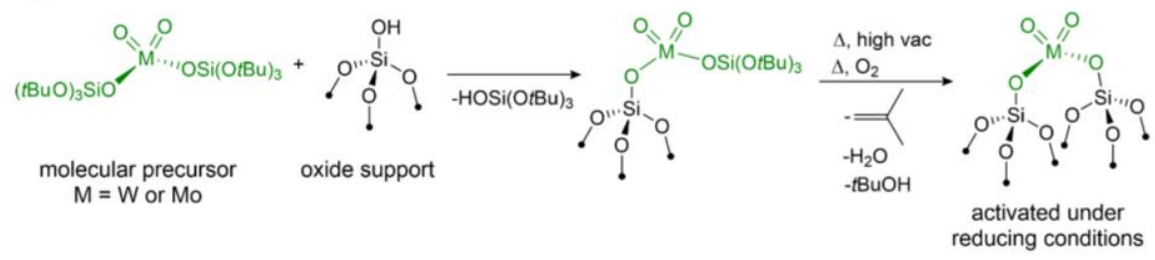

(d) Well-defined supported alkylidenes
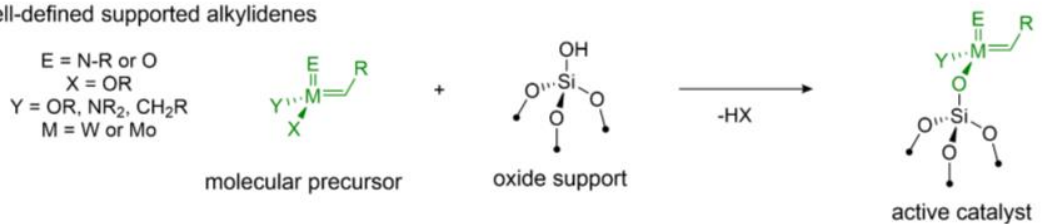

Figure 1. State-of-the-art in olefin metathesis: (a) Molecular group 6 metal alkylidene olefin metathesis catalysts. (b) Surface species proposed on supported Mo or W oxide precatalysts and proposed structure of the active site for olefin metathesis. Surface organometallic chemistry (SOMC) routes for preparation of (c) monodispersed metal oxo precatalyst sites or (d) well-defined supported metal alkylidenes. 
valent metal oxo species in the presence of olefins (Figure $1 b$ ). ${ }^{8}$ Recent work leveraging the principles of surface organometallic chemistry (SOMC) $)^{12,13}$ has enabled the generation of atomically dispersed and isolated $\mathrm{W}(\mathrm{VI})$ and $\mathrm{Mo}(\mathrm{VI})$ oxo sites as models for oxide catalysts prepared through traditional synthetic approaches (Figure 1c). ${ }^{14,15}$ Upon activation in situ with an organosilicon reducing agent, these species display low temperature activity $\left(<100^{\circ} \mathrm{C}\right)$ originating from the formation of $\mathrm{M}(\mathrm{IV})$ species and their in situ conversion to M(VI) oxo alkylidenes upon reaction with the olefin substrate. ${ }^{14,15}$ Yet, such monodispersed metal oxo catalysts still exhibit significantly lower activity (by several orders of magnitude) than well-defined silica-supported alkylidenes prepared via SOMC (Figure 1d). Given the similar electronic characteristics of surface siloxides and some of the corresponding molecular ligands, ${ }^{16}$ the different reaction patterns are puzzling and suggest that other factors must be at play besides the smaller number of active in supported metal oxide based catalysts (5-10\% vs. ca. 100\% for well-defined alkylidenes). ${ }^{8}$ In fact, even well-defined supported alkylidenes can exhibit low catalytic performances in a few instances for metathesis of olefins in the liquid phase, e.g. low activity in ring-closing metathesis reactions ${ }^{17}$ and slow initiation for supported cationic W oxo alkylidenes when using very low catalyst loadings. ${ }^{18}$ In both cases, restricted dynamics of surface species have been proposed to explain these reactivity patterns.

In order to expand the application of supported catalysts and to better understand the influences of dynamics on activity, we have investigated the low-temperature $\left(<100^{\circ} \mathrm{C}\right)$ metathesis activities of a series of supported and molecular Mo-based olefin metathesis catalysts towards long-chain linear $\alpha$-olefins $\left(\mathrm{C}_{8-}\right.$ $\mathrm{C}_{20}$ ), of importance to the Shell higher-olefin process (SHOP) and related processes. ${ }^{19-22}$ We observe a surprisingly vast difference in activity patterns among molecular and supported catalysts, including silicasupported and molecular Mo alkylidenes as well as reduced silica-supported Mo oxo species, which reveals the importance of olefin-surface interactions on reactivity. Specifically, the supported Mo oxo systems exhibit strong dependencies of activity as a function of olefin chain length, in contrast to the welldefined supported or molecular Mo alkylidenes. Solid-state $2 \mathrm{D}$ heteronuclear ${ }^{13} \mathrm{C}-{ }^{1} \mathrm{H}$ and ${ }^{29} \mathrm{Si}-{ }^{1} \mathrm{H}$ NMR correlation analyses of post-reaction catalysts, with sensitivity enhanced by state-of-the-art fast magic angle spinning (MAS) and ${ }^{1} \mathrm{H}$ detection ${ }^{23,24}$ or dynamic nuclear polarization (DNP) $)^{25,26}$ techniques, 
complemented by FTIR spectroscopy and molecular dynamics calculations, uncover the strong adsorption of long-chain olefin metathesis hydrocarbon products onto the silica support near surface-OH sites. These interactions result in decreased reaction rates with increasing chain length in the case of supported Mo oxides as a result of the stronger adsorption of the internal di-substituted olefin product.

\section{Results and Discussion}

\section{Activity trends of Mo oxo based (pre)catalysts for metathesis of linear $\alpha$-olefins}

We first evaluated the trends in catalyst activity for the metathesis of linear $\alpha$-olefins for silica-supported Mo oxide-based catalysts. We focused on a broad range of linear $\alpha$-olefins $\left(\mathrm{C}_{8}-\mathrm{C}_{20}\right)$ that can be obtained by olefin oligomerization ${ }^{19,27,28}$ or Fischer-Tropsch ${ }^{21,22,29}$ processes. Primarily molybdenum-based catalysts were tested as they are known to be more efficient for terminal olefin metathesis than their $\mathrm{W}$ ana$\operatorname{logues}^{30,31}$ (vide infra) due to better tolerance for ethylene. ${ }^{32}$ Monodispersed Mo dioxo species (1.56 wt $\%$ Mo) were generated via an SOMC approach as previously reported ${ }^{15}$ and activated at room temperature by prereduction with 2 equivalents on a per Mo basis of the molecular organosilicon reductant 1-methyl3,6-bis(trimethylsilyl)-1,4-cyclohexadiene $(\mathrm{MBTCD}),{ }^{14,33}$ yielding a catalyst denoted $(\equiv \mathbf{S i O})_{2} \mathbf{M o}(=\mathbf{O})_{2}-$ red (Fig. 2a). For comparison, a classical silica-supported Mo oxide catalyst was prepared by an incipient wetness impregnation approach followed by calcination under synthetic air. ${ }^{34}$ This oxidized precatalyst contains $3.65 \mathrm{wt} \%$ Mo, was also activated for low-temperature metathesis by 2 equivalents of the same

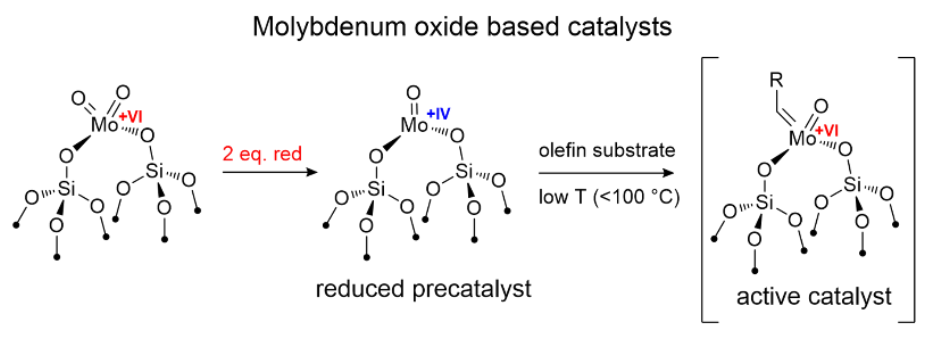

(a) Surface organometallic chemistry route: $\quad(\equiv \mathrm{SiO})_{2} \mathrm{Mo}(=\mathrm{O})_{2}$-red

(b) Incipient wetness impregnation route:

$\mathrm{MoO}_{x} / \mathrm{SiO}_{2}$-red
Well-defined metal alkylidene catalysts
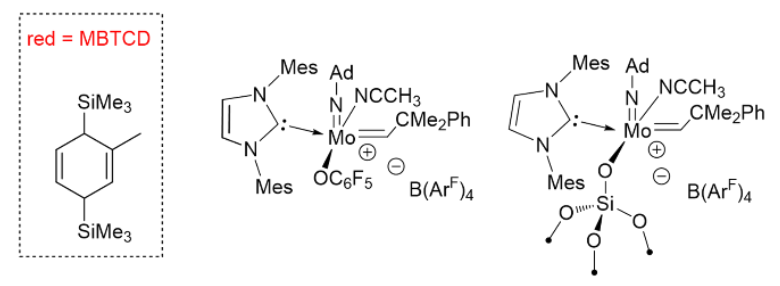

(c) Molecular $\mathrm{Mo}^{+}$

(c) Supported $\mathrm{Mo}^{+} / \mathrm{SiO}_{2}$

Figure 2. Molybdenum oxide-based catalysts prepared via (a) an SOMC-based approach, $(=\mathbf{S i O})_{2} \mathbf{M o}(=\mathbf{O})_{2}$-red, or (b) a conventional incipient wetness impregnation approach, $\mathbf{M o O}_{x} / \mathbf{S i O}_{2}$ red. Well-defined cationic Mo imido alkylidene NHC catalysts in (c) molecular (Mo ${ }^{+}$) and (d) supported $\left(\mathrm{Mo}^{+} / \mathrm{SiO}_{2}\right)$ forms. 
organosilicon reductant (MBTCD) and is denoted $\mathbf{M o O}_{\mathbf{x}} / \mathbf{S i O}_{2}$-red (Fig. 2b). Both $(\equiv \mathbf{S i O})_{2} \mathbf{M o}(=\mathbf{O})_{2}$ and $\mathrm{MoO}_{\mathbf{x}} / \mathrm{SiO}_{2}$ contain residual isolated surface $\mathrm{Si}-\mathrm{OH}$ species, as evidenced by their FTIR spectra in Figures S1 and S2. Based on previous X-ray Absorption Spectroscopic (XAS) analyses, ${ }^{15,35}$ both SOMC and incipient wetness impregnation approaches yield predominantly isolated Mo dioxo surface species, though the activity of the resulting precatalysts is modestly different (Table S1), suggesting differences in the quantities of active sites generated.

The reactivities of the catalysts based on metal oxo precatalysts, $(=\mathrm{SiO})_{2} \mathbf{M o}(=\mathbf{O})_{2}-\mathbf{r e d}$ and $\mathrm{MoO}_{\mathbf{x}} / \mathbf{S i O}_{2}-$ red, were assessed at both $70{ }^{\circ} \mathrm{C}$ and $30^{\circ} \mathrm{C}$. All reactions were conducted in batch mode under $\mathrm{N}_{2}$ atmosphere. 1,2-Dichlorobenzene was chosen as solvent due its low vapor pressure. Liquid phase olefin metathesis reaction rates for the metal oxo based materials were found to generally depend on the precise reaction conditions, particularly the purity of the olefin stock solutions. Highest reaction rates were observed when the olefin substrates were freshly purified immediately before the catalytic reaction tests according to a rigorous purification protocol (see Experimental Section for details). ${ }^{30}$

Both $(=\mathrm{SiO})_{2} \mathbf{M o}(=\mathbf{O})_{2}$-red and $\mathbf{M o O}_{\mathbf{x}} / \mathbf{S i O}_{2}$-red are competent for the metathesis of linear $\alpha$-olefins in the liquid phase at low temperature. For 1-nonene as a prototypical substrate, $(\equiv \mathbf{S i O})_{2} \mathbf{M o}(=\mathbf{O})_{2}$-red exhibits maximum product formation rates (measured after ca. 10 minutes of reaction time with no observed induction period) of 2.6 and $2.0\left(\mathrm{mmol}\right.$ product $\left.[\mathrm{mmol} \mathrm{Mo}]^{-1}[\mathrm{~min}]^{-1}\right)$ at $70{ }^{\circ} \mathrm{C}$ and $30{ }^{\circ} \mathrm{C}$, respectively (Figures S4 and S5, Table S1). The W-based analogue $(\equiv \mathbf{S i O})_{2} \mathbf{W}(=\mathbf{O})_{2}-$ red $^{14}$ was also tested at $70{ }^{\circ} \mathrm{C}$ for comparison but was found to exhibit lower activity for 1-nonene metathesis with a maximum rate of 0.9 (mmol product $[\mathrm{mmol} \mathrm{W}]^{-1}[\mathrm{~min}]^{-1}$ ) (Figure S6, Table S1). The lower activity of the W based catalyst compared to the Mo analogue is consistent with recent studies on well-defined silica-supported alkylidenes, ${ }^{30,31}$ which found that Mo-based catalysts are typically much more active for the metathesis of terminal olefins because of the lower stability of off-cycle square-planar (SP) metallacycle intermediates generated in the presence of ethylene. ${ }^{32}$ By comparison, $\mathbf{M o O}_{\mathbf{x}} / \mathbf{S i O}_{2}$-red exhibits initial 1-nonene product formation rates of 3.9 and $0.71\left(\mathrm{mmol}\right.$ product $\left.[\mathrm{mmol} \mathrm{Mo}]^{-1}[\mathrm{~min}]^{-1}\right)$ at $70{ }^{\circ} \mathrm{C}$ and $30{ }^{\circ} \mathrm{C}$, respectively 
(Figures S7 and S8, Table S1). For both $(=\mathbf{S i O})_{2} \mathbf{M o}(=\mathbf{O})_{2}-\mathbf{r e d}$ and $\mathbf{M o O}_{\mathbf{x}} / \mathbf{S i O}_{2}-\mathbf{r e d}$, significant conversion $(6-11 \%)$ is observed to internal olefin isomers of the desired 1-nonene metathesis product at $70{ }^{\circ} \mathrm{C}$ (Table S1), suggesting formation of Mo hydrides that promote isomerization of the long-chain internal olefins. ${ }^{36}$ Improved product selectivities were observed at $30{ }^{\circ} \mathrm{C}(>98 \%)$ compared to $70{ }^{\circ} \mathrm{C}$ (Table S1). Additionally, substantial solvent evaporation was observed at $70{ }^{\circ} \mathrm{C}$ after long reaction times when open reaction vials were used to allow for release of ethylene. Accordingly, reactions were also run at $70{ }^{\circ} \mathrm{C}$ in closed reaction vials, yielding higher initial reaction rates but lower overall conversions (Table S2). The product $E$ and $Z$ selectivities of the two catalysts based on silica-supported Mo oxo species, $(=\mathrm{SiO})_{2} \mathrm{Mo}(=\mathbf{O})_{2}-\mathbf{r e d}$ and $\mathrm{MoO}_{\mathbf{x}} @$ SiO2-red, were very similar at low conversions, ca. 70\% and 30\%, respectively $\left(E / Z\right.$ ratio $\sim 2.1$ at $70{ }^{\circ} \mathrm{C}$ and $\sim 2.3$ at $30^{\circ} \mathrm{C}$, Fig. S9 and S10, Table S1). Since stereoselectivity in olefin metathesis at low conversions depends directly on the structure of the active site ${ }^{37}$ these similar values corroborate that both catalysts have similar active site structures.

To assess the influence of olefin chain length on activity, $(=\mathrm{SiO})_{2} \mathbf{M o}(=\mathbf{O})_{2}$-red was tested as a catalyst for the metathesis of the linear $\alpha$-olefins 1-octene, 1-nonene, 1-tridecene, 1 - hexadecene, and 1-eicosene. Maximum product formation rates of 9.9, 7.8, 4.5, 2.7, and $0.9\left(\mathrm{mmol}\right.$ product $[\mathrm{mmol} \mathrm{Mo}]^{-1}\left[\mathrm{~min}^{-1}\right)$ at $70{ }^{\circ} \mathrm{C}$ (in closed reaction vials) and 3.2, 2.6, 2.0, 1.6, and $0.4\left(\mathrm{mmol}\right.$ product $\left.[\mathrm{mmol} \mathrm{Mo}]^{-1}[\mathrm{~min}]^{-1}\right)$ at 30 ${ }^{\circ} \mathrm{C}$ (in open reaction vials) were observed after 10 minutes reaction time. Lower substrate concentrations $(0.5 \mathrm{M})$ were used for the 1-eicosene reaction tests to mitigate the poor solubility of the very long-chain metathesis product. The initial product formation rates are compared in Figure $3 \mathrm{a}$, the kinetic profiles are shown in Figures S11-S20, and catalytic reaction data are summarized in Tables S2 and S3. MoOr@SiO2red was also tested for 1-nonene, 1-tridecene, and 1-hexadecene metathesis at $30{ }^{\circ} \mathrm{C}$ and showed trends similar to $(=\mathbf{S i O})_{2} \mathbf{M o}(=\mathbf{O})_{2}$-red, though with somewhat lower activity on a per Mo basis and in some cases an induction period (Figures S21-S23, Table S4). As shown in Figure 3a, reaction rates for $(\equiv \mathrm{SiO})_{2} \mathrm{Mo}(=\mathbf{O})_{2}$-red decrease monotonically as a function of olefin chain length for the entire substrate series studied here at both $70{ }^{\circ} \mathrm{C}$ and $30{ }^{\circ} \mathrm{C}$. 
While ( $\equiv \mathbf{S i O})_{2} \mathbf{M o}(=\mathbf{O})_{2}$-red exhibits overall promising activity and selectivity in the metathesis of linear $\alpha$-olefins at low temperature $\left(<100^{\circ} \mathrm{C}\right)$, we sought to understand the origin of its reduced metathesis activity for long-chain, terminal $\alpha$-olefins. We hypothesized three possible explanations: Hypothesis (A): the intermediates on the catalytic cycle are energetically disfavored for longer chain olefins, e.g. due to steric factors; Hypothesis (B): initiation of the Mo oxo (IV) species to form Mo oxo alkylidenes is chainlength dependent; or Hypothesis $(\mathrm{C})$ : there is a chain-length dependence for the interactions of olefinic

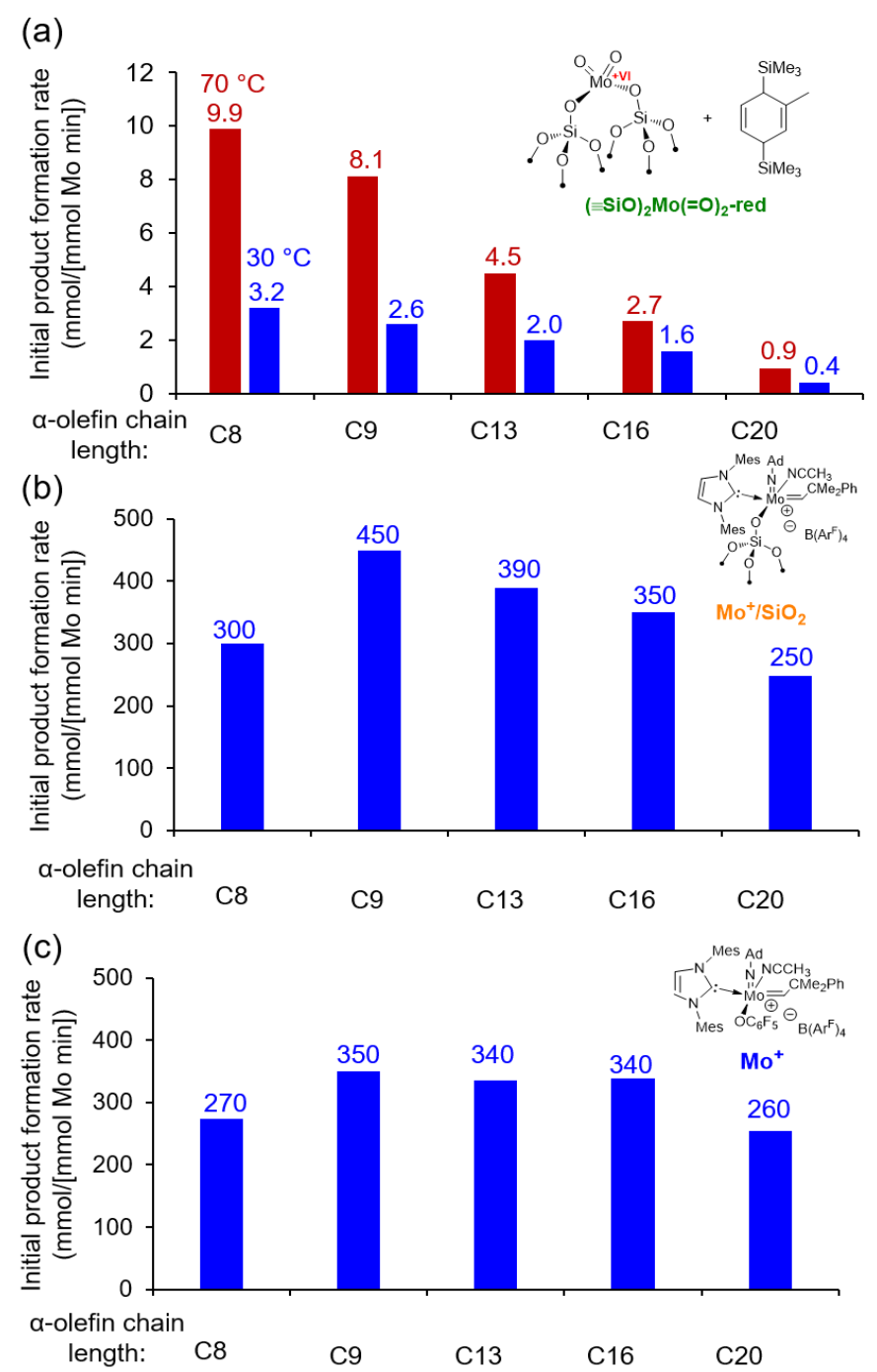

Figure 3. Initial product formation rates for metathesis of linear alpha olefins catalyzed by (a) $(\equiv \mathbf{S i O})_{2} \mathbf{M o}(=\mathbf{O})_{2}$-red at $70{ }^{\circ} \mathrm{C}$ (red) and $30{ }^{\circ} \mathrm{C}$ (blue) or well-defined Mo imido alkylidene NHC catalysts (b) $\mathrm{Mo}^{+} / \mathrm{SiO}_{2-700}$ or (c) molecular $\mathrm{Mo}^{+}$. All reactions were carried out under an $\mathrm{N}_{2}$ atmosphere, in closed $\left(70{ }^{\circ} \mathrm{C}\right)$ or open $\left(30^{\circ} \mathrm{C}\right)$ batch reactors containing $2.5 \mathrm{~mL}$ of substrate stock solution in 1,2-dichlorobenzene. $1 \mathrm{M}$ substrate stock solutions were used for 1-octene, 1-nonene, 1-tridecene, and 1-hexadecene, with substrate: Mo ratios of ca. 1000:1 for $(=\mathbf{S i O})_{2} \mathbf{M o}(=\mathbf{O})_{2}$-red and ca. 5000:1 for $\mathbf{M o}^{+}$and $\mathbf{M o}^{+} / \mathbf{S i O}_{2}-$ 700. For 1-eicosene, a $0.5 \mathrm{M}$ substrate stock solution was used with substrate: Mo ratios of ca. 500:1 for $(\equiv \mathbf{S i O})_{2} \mathbf{M o}(=\mathbf{O})_{2}$-red and ca. 2500:1 for $\mathbf{M o}^{+}$and $\mathbf{M o}^{+} / \mathbf{S i O}_{2}$. 
products and the catalyst surface that influences reactivity. In the case of Hypothesis (B), we would expect similar maximum product formation rates for all olefins, with different induction periods due to different rates of catalyst initiation. As no induction periods are observed for this catalyst Hypothesis (B) seems unlikely. To investigate Hypothesis (A), we measured the reactivity trends of well-defined metal alkylidene-based catalysts in molecular and supported forms.

\section{Activity of well-defined molecular and supported Mo alkylidene olefin metathesis catalysts}

To assess the influence of active site structure and surface composition on linear $\alpha$-olefin metathesis activity, we tested for comparison a well-defined and highly active cationic Mo imido alkylidene $N$-heterocyclic carbene (NHC) catalyst in both molecular $\left(\mathbf{M o}^{+}\right)^{38}$ and silica-supported $\left(\mathbf{M o}^{+} / \mathbf{S i O}_{2}\right)^{39}$ forms (Figure 2c,d). By comparison to the catalysts based on supported Mo oxides, those based on well-defined Mo alkylidenes $\left(\mathrm{Mo}^{+}\right.$and $\left.\mathbf{M o}^{+} / \mathbf{S i O}_{2}\right)$ exhibited orders of magnitude higher activity at $30^{\circ} \mathrm{C}$ with no induction period, consistent with the presence of the initiating alkylidene ligand and the optimized ligand sets of these catalysts. While the increased reaction rates can be due to the specific nature and the number of the active sites, the different trends in reactivity as a function of olefin chain length are noteworthy. Specifically, the initial product formation rates for $\mathbf{M o}^{+} / \mathbf{S i O}_{2-700}$ (measured after 3 minutes reaction time) varies only slightly from $300,450,380,340$, and $250\left(\mathrm{mmol}\right.$ product $[\mathrm{mmol} \mathrm{Mo}]^{-1}\left[\mathrm{~min}^{-1}\right)$ for 1-octene, 1nonene, 1-tridecene, 1-hexadecene, and 1-eicosene, respectively (Figure 3b). By comparison, the molecular catalyst $\mathrm{Mo}^{+}$exhibited similar maximum product formation rates (measured after 3 minutes reaction time) of $270,350,340,340$, and $260\left(\mathrm{mmol}\right.$ product $\left[\mathrm{mmol} \mathrm{Mo}^{-1}\left[\mathrm{~min}^{-1}\right)\right.$ for 1-octene, 1-nonene, 1tridecene, 1-hexadecene, and 1-eicosene, respectively (Figure 3c). Additional details of the catalytic tests are provided in Figures S24-S33 and Tables S5 and S6. Based on repeated measurements, the uncertainty of the product formation rates was estimated to be $\pm 30\left(\right.$ mmol product $\left.[\mathrm{mmol} \mathrm{Mo}]^{-1}[\mathrm{~min}]^{-1}\right)$ (see Fig. S33 for details). In general, the well-defined cationic alkylidene catalysts were highly efficient in both molecular and supported forms: for each of the linear $\alpha$-olefin substrates tested, $\mathbf{M o}^{+}$and $\mathbf{M o}^{+} / \mathrm{SiO}_{2-700}$ reached $>40 \%$ conversion within the first three minutes of the reaction period. The supported catalyst 
$\mathbf{M o}^{+} / \mathrm{SiO}_{2}$ exhibited equivalent or higher activity for each substrate compared to $\mathbf{M o}^{+}$, consistent with previous comparisons of well-defined supported and molecular alkylidenes. ${ }^{13,39}$ In contrast to $(\equiv \mathrm{SiO})_{2} \mathrm{Mo}(=\mathbf{O})_{2}$-red and $\mathrm{MoO}_{\mathbf{r}} @ \mathrm{SiO}_{2}$-red, the molecular catalyst $\mathrm{Mo}^{+}$showed little dependence of activity on substrate chain length, with a slight optimum for olefins in the C9-C16 range. Thus, there seems to be no intrinsic limitation for the metathesis of long chain olefins related to the catalytic intermediates themselves, enabling us to discard Hypothesis (A) posed above. $\mathbf{M o}^{+} / \mathbf{S i O}_{2}-\mathbf{7 0 0}$ exhibited an optimum in activity for 1-nonene, as well as a modest decrease in activity as a function of substrate chain length from 1-nonene to 1-eicosene, though not as pronounced as that observed for $\left.(\equiv \mathbf{S i O})_{2} \mathbf{M o}(=\mathbf{O})\right)_{2}-\mathbf{r e d}$ at $30^{\circ} \mathrm{C}$ (Figure S34). Overall, the reactivity trend of $\mathbf{M o}^{+} / \mathbf{S i O}_{2}$ appears closer to the molecular $\mathbf{M o}^{+}$than the supported metal oxide catalysts. Based on these observations, we investigated Hypothesis (C): that the reaction trends of the supported Mo oxo and alkylidene based catalysts arise in large part from differences in surface dynamics and olefin adsorption relating to the distinct surface compositions of the catalysts, which could also account for the decreasing activity with olefin chain length of the Mo oxide system.

\section{Metathesis products adsorbed on post-reaction metathesis catalysts}

To assess the adsorption and interactions of olefins on these catalysts, FTIR and solid-state NMR spectroscopies were used to probe the structure, dynamics, and interactions of the organics on the supported catalysts after reaction. FTIR and $1 \mathrm{D}{ }^{1} \mathrm{H}$ solid-state $\mathrm{NMR}$ analyses of $(=\mathbf{S i O})_{2} \mathbf{M o}(=\mathbf{O})_{2}$-red after reaction show the presence of organic species (Fig. S35-S37), which increase in relative quantity as a function of reaction time. This is corroborated by elemental analysis, which further indicates that the surface coverage of organic approaches monolayer coverage as reaction time increases (Table S7). Solid-state 2D heteronuclear correlation NMR spectra were therefore acquired to establish the types of organic species and their surface interactions by leveraging NMR sensitivity enhancements provided by either fast-MAS and ${ }^{1} \mathrm{H}$ detection ${ }^{23,24}$ or by dynamic nuclear polarization (DNP). ${ }^{25,26}$ For example, Figure 4 shows the solidstate 2D ${ }^{1} \mathrm{H}\left\{{ }^{13} \mathrm{C}\right\}$ dipolar heteronuclear multiple quantum correlation (D-HMQC) spectrum of 
$(\equiv \mathbf{S i O})_{2} \mathbf{M o}(=\mathbf{O})_{2}$-red after $24 \mathrm{~h}$ reaction at $30{ }^{\circ} \mathrm{C}$ with 1 -hexadecene in 1,2-dichlorobenzene (ca. $80 \%$ conversion). Prior to the solid-state NMR analysis, the catalyst was washed with benzene to remove weakly bound surface species and dried under high vacuum (see Experimental section for details). Fast MAS $(50 \mathrm{kHz})$ and indirect detection provide high ${ }^{13} \mathrm{C}$ NMR sensitivity and resolution, enabling detection of the $2 \mathrm{D}$ spectrum of the surface-bound organic species at natural abundance $(1.1 \%){ }^{13} \mathrm{C}$. The $2 \mathrm{D}{ }^{1} \mathrm{H}\left\{{ }^{13} \mathrm{C}\right\}$ spectrum shows well-resolved correlated signals that can each be assigned to organic moieties on the catalyst surface. Specifically, the correlated signal at $-1 \mathrm{ppm}$ in the ${ }^{13} \mathrm{C}$ dimension and $0.3 \mathrm{ppm}$ in the ${ }^{1} \mathrm{H}$ dimension is assigned to surface $-\mathrm{OSi}\left(\mathrm{CH}_{3}\right)_{3}$ moieties resulting from reaction of the organosilicon reductant. The ${ }^{1} \mathrm{H}$ signals at $1.0,1.5$, and $2.2 \mathrm{ppm}$ are each correlated to ${ }^{13} \mathrm{C}$ signals at $13,21-30$, and $32 \mathrm{ppm}$, respectively, which are assigned to $-\mathrm{CH}_{3}$, aliphatic $-\mathrm{CH}_{2}-$, and allylic $-\mathrm{CH}_{2}$ - moieties, respectively, while the ${ }^{1} \mathrm{H}$ signal at $5.6 \mathrm{ppm}$ is correlated to a ${ }^{13} \mathrm{C}$ at $132 \mathrm{ppm}$ and is assigned to internal olefinic species. The absence of ${ }^{13} \mathrm{C}$ or ${ }^{1} \mathrm{H}$ signals from other olefinic species and the relatively narrow linewidth of the ${ }^{1} \mathrm{H}$ signal at $5.6 \mathrm{ppm}$ indicates that only a single type of internal olefin is present at the catalyst surface, most likely the bulky C30 product of 1-hexadecene metathesis, 15-triacontene. Differences between the $E$ - and $Z$-stereoisomers cannot be resolved in this case as they are expected to be separated by $<0.1 \mathrm{ppm}$ in ${ }^{1} \mathrm{H}$ NMR and $<0.5 \mathrm{ppm}$ in ${ }^{13} \mathrm{C}$ NMR. This internal olefin is strongly adsorbed on to the catalyst surface, as further corroborated by ${ }^{1} \mathrm{H} T_{2}$ spin-spin relaxation time analyses (Table S8), which are sensitive to the dynamics of surface species. ${ }^{40}$ The $T_{2}$ relaxation times of the adsorbed olefins are found to be quite short $(<2 \mathrm{~ms})$ consistent with strong adsorption and hindered dynamics of the surface-bound organics. The 1D and $2 \mathrm{D}{ }^{1} \mathrm{H}\left\{{ }^{13} \mathrm{C}\right\}$ MAS NMR spectra and analyses thus establish that the predominant surface-bound organic component on post-reaction $(\equiv \mathbf{S i O})_{2} \mathbf{M o}(=\mathbf{O})_{2}$-red is the bulky olefin metathesis product, which adsorbs strongly under mild reaction conditions, thereby limiting catalyst efficiency.

This adsorption of the olefin metathesis products appears to be competitive with the 1,2-dichlorobenzene solvent. This is evidenced by comparison of the ${ }^{1} \mathrm{H}$ MAS NMR spectra of $(\equiv \mathbf{S i O})_{2} \mathbf{M o}(=\mathbf{O})_{2}$-red after different reaction times with 1-hexadecene or 1-nonene in Fig. S36 and S37. The spectra all exhibit a ${ }^{1} \mathrm{H}$ 


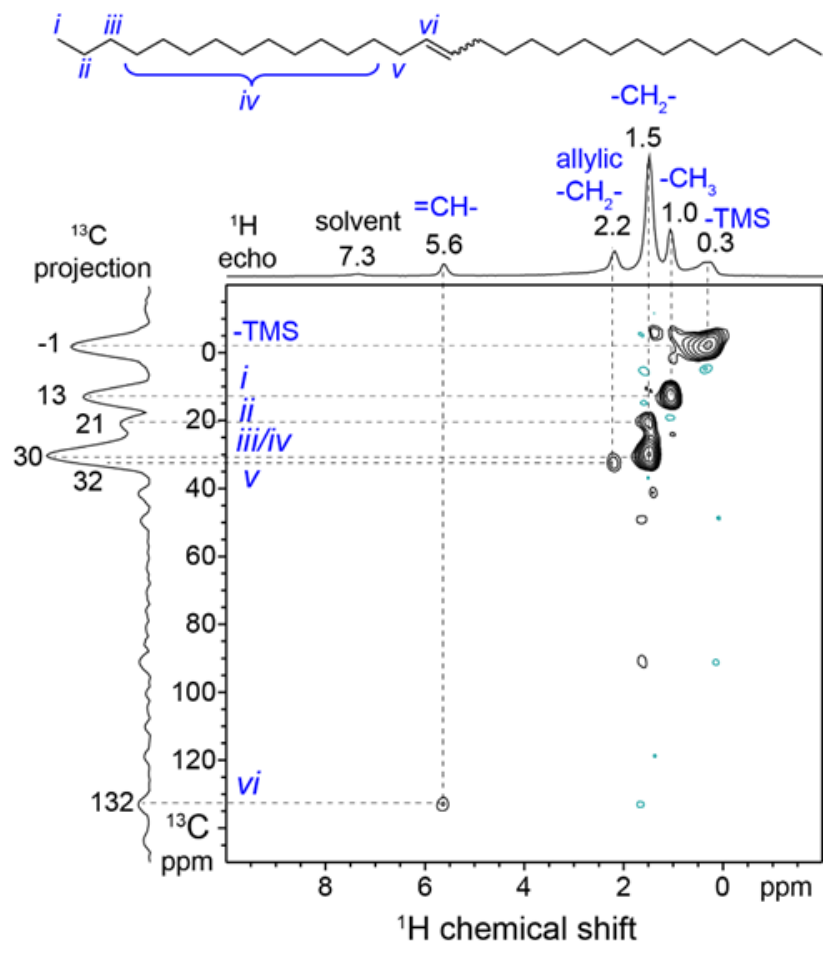

Figure 4. Solid-state $2 \mathrm{D}{ }^{1} \mathrm{H}\left\{{ }^{13} \mathrm{C}\right\}$ D-HMQC NMR correlation spectrum of $\left.(=\mathbf{S i O})_{2} \mathbf{M o}(=\mathbf{O})\right)_{2}$-red after $24 \mathrm{~h}$ reaction with 1 -hexadecene in 1,2 -dichlorobenzene at $30{ }^{\circ} \mathrm{C}$ (ca. $80 \%$ conversion), $3 \mathrm{x}$ washing with $\mathrm{C}_{6} \mathrm{H}_{6}$, and drying under high vacuum. The spectrum was acquired at $16.4 \mathrm{~T}, 50 \mathrm{kHz} \mathrm{MAS}, 280 \mathrm{~K}$, and with 60 rotor periods $(1.2 \mathrm{~ms})$ for ${ }^{13} \mathrm{C}-{ }^{1} \mathrm{H}$ recoupling. A $1 \mathrm{D}{ }^{1} \mathrm{H}$ echo MAS NMR spectrum acquired under the same conditions is shown along the horizontal axis for comparison. All correlated signals are assigned to surface trimethylsilyl (-TMS) or to the internal olefin product of 1-hexadecene self-metathesis as indicated by the Roman numeral labels on the molecular structure above.

signal at $7.3 \mathrm{ppm}$, which is assigned to residual adsorbed 1,2-dichlorobenzene solvent. However, for the catalyst after 1-nonene metathesis this signal was greatly increased in intensity relative to the ${ }^{1} \mathrm{H}$ signals from adsorbed olefinic species, while for the catalyst after 1-hexadecene metathesis the solvent signal was greatly diminished. After increasing 1-hexadecene metathesis reaction times, the signal from dichlorobenzene decreases in intensity relative to the signals from adsorbed olefins (Fig. S36), consistent with increased relative coverage of olefin species.

The nature of the olefin-surface interaction was further elucidated by analysis of $2 \mathrm{D}{ }^{29} \mathrm{Si}\left\{{ }^{1} \mathrm{H}\right\}$ and ${ }^{13} \mathrm{C}\left\{{ }^{1} \mathrm{H}\right\}$ heteronuclear correlation (HETCOR) spectra leveraging DNP-NMR techniques at low temperature. DNPNMR provides greatly enhanced NMR signal sensitivity from surfaces and enables acquisition of 2D NMR correlation spectra that probe organic-inorganic interactions of adsorbed and surface species. ${ }^{41,42}$ Though DNP-NMR techniques have been widely used for analysis of diverse organic-inorganic hybrid 
materials including colloidal nanoparticles ${ }^{43}$ and catalysts, ${ }^{44,45}$ there are surprisingly few examples of its application to characterize molecular adsorption phenomena at surfaces,${ }^{46}$ despite the critical importance of such phenomena for catalysis.

The DNP-enhanced $1 \mathrm{D}^{13} \mathrm{C}\left\{{ }^{1} \mathrm{H}\right\}$ CP-MAS spectrum of $(=\mathbf{S i O})_{2} \mathbf{M o}(=\mathbf{O})_{2}$-red after 4 hours reaction with 1-hexadecene (Fig. S38) shows similar ${ }^{13} \mathrm{C}$ signals to those observed in Figure 3, though slightly broader due to slower molecular dynamics under the low-temperature conditions ${ }^{40}$ In addition to the ${ }^{13} \mathrm{C}$ signal at $128 \mathrm{ppm}$ of internal olefinic and/or aromatic species, a ${ }^{13} \mathrm{C}$ signal is detected at $116 \mathrm{ppm}$ from terminal olefinic moieties, evidencing the co-existence of a distribution of olefin species adsorbed on the catalyst surface at intermediate reaction times (i.e., low conversions), consistent with the room-temperature 1D ${ }^{1} \mathrm{H}$ MAS NMR analyses (Fig. S36). This suggests that metathesis activity of liquid-phase olefins at low temperatures is largely mediated by desorption of the internal olefin product, with a pool of adsorbed olefin molecules building up on the catalyst surface at longer reaction times.

Specifically, surface $\mathrm{Si}-\mathrm{OH}$ species are directly identified as olefin adsorption sites in $(=\mathrm{SiO})_{2} \mathbf{M o}(=\mathbf{O})_{2}$ red by analysis of $2 \mathrm{D}^{29} \mathrm{Si}\left\{{ }^{1} \mathrm{H}\right\}$ DNP-HETCOR spectra in Figure 5, which probe ${ }^{29} \mathrm{Si}^{1}{ }^{1} \mathrm{H}$ interactions over sub-nanometer length scales that vary as a function of ${ }^{29} \mathrm{Si}^{1}{ }^{1} \mathrm{H}$ contact time. The different ${ }^{1} \mathrm{H}$ signals are resolved and assigned based on the $2 \mathrm{D}{ }^{13} \mathrm{C}\left\{{ }^{1} \mathrm{H}\right\}$ HETCOR spectrum in Figure S38 (see Supporting Information for details). At short ${ }^{29} \mathrm{Si}^{1}{ }^{1} \mathrm{H}$ contact times ( $0.5 \mathrm{~ms}$, Fig. 5a), weak ${ }^{29} \mathrm{Si}$ signals are detected at -105 , -113 , and $-121 \mathrm{ppm}$, which are assigned based on literature ${ }^{47,48}$ to partially crosslinked $Q^{3}$ species and two different types of fully crosslinked surface $Q^{4}$ species, respectively. The $Q^{n}$ notation indicates a silicon atom in a tetrahedral environment bonded to four oxygen atoms, of which $n$ are bonded to another silicon atom and $4-n$ are incompletely crosslinked, e.g. H terminated. Notably, the ${ }^{29} \mathrm{Si}$ signals at -105 and -113 ppm are correlated with ${ }^{1} \mathrm{H}$ signals at 4.9 and $5.3 \mathrm{ppm}$ from olefinic species, which directly establishes the sub-nanometer proximities and mutual interactions of surface silanols and olefinic moieties of adsorbed molecules, as depicted schematically in the inset to Fig. 5a. The short contact times used make this measurement principally sensitive to interactions over distances of $<0.5 \mathrm{~nm}$, indicating that the olefinic moieties of the surface-bound olefins interact preferentially with surface silanol species over sub- 


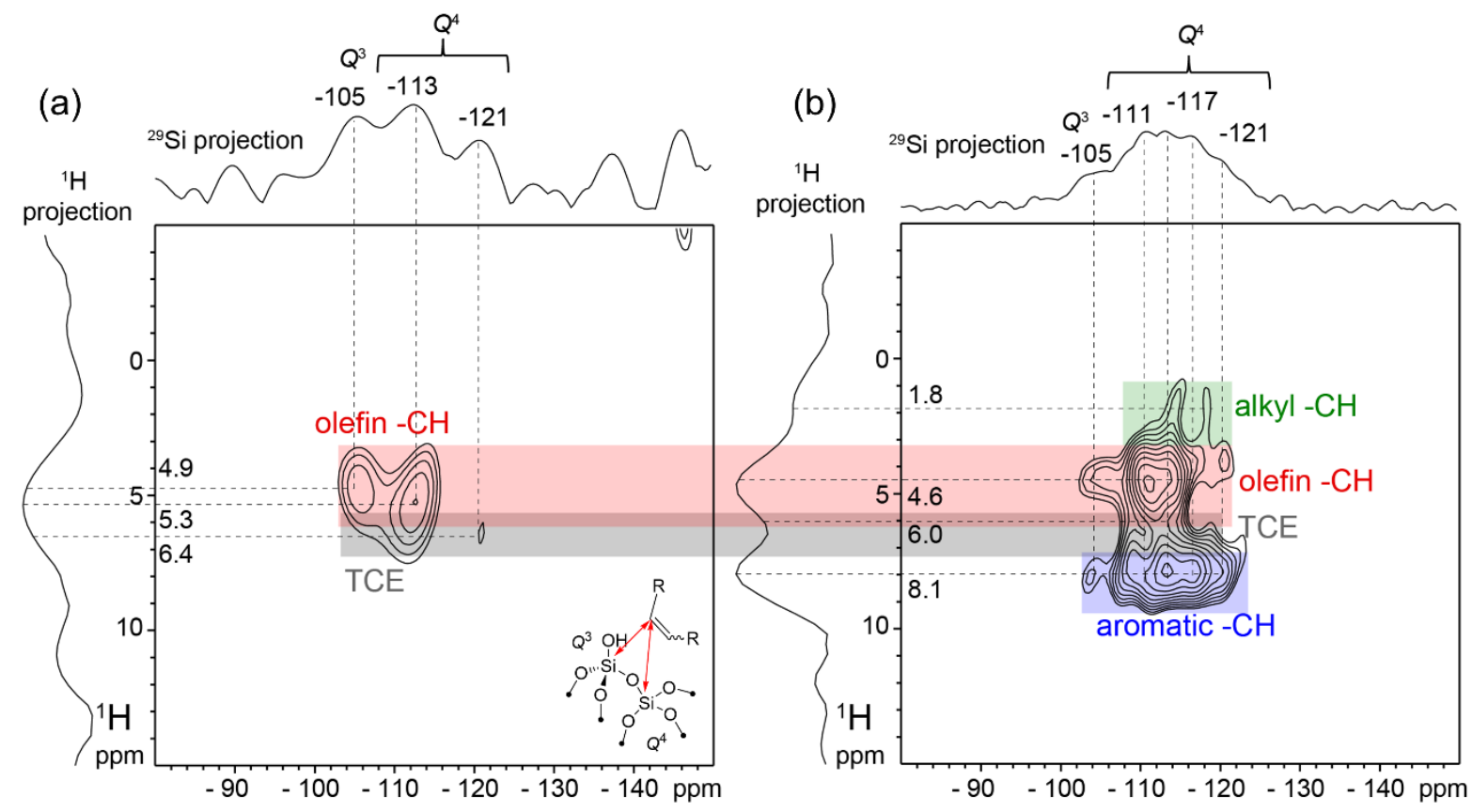

Figure 5. Solid-state $2 \mathrm{D}{ }^{29} \mathrm{Si}\left\{{ }^{1} \mathrm{H}\right\}$ DNP-HETCOR spectra of $(\equiv \mathbf{S i O})_{2} \mathbf{M o}(=\mathbf{O})_{2}$-red after 4 h reaction with 1-hexadecene in 1,2-dichlorobenzene at $30{ }^{\circ} \mathrm{C}, 3 \mathrm{x}$ washing with $\mathrm{C}_{6} \mathrm{H}_{6}$, and drying under high vacuum. The $2 \mathrm{D}$ spectra were acquired at $14.1 \mathrm{~T}, 12.5 \mathrm{kHz}$ MAS, $100 \mathrm{~K}$, under continuous microwave irradiation at $395 \mathrm{GHz}$, in the presence of $16 \mathrm{mM}$ TEKPol biradical in 1,1,2,2-tetrachloroethane (DNP solvent), and with ${ }^{29} \mathrm{Si}-{ }^{1} \mathrm{H}$ contact times of (a) $0.5 \mathrm{~ms}$ and (b) $5 \mathrm{~ms}$. The schematic in (a) shows interactions of an olefin moiety with surface $\mathrm{Si}-\mathrm{OH}\left(Q_{3}\right)$ and fully crosslinked $\left(Q_{4}\right)$ surface silicate species, consistent with the correlated signals in the $2 \mathrm{D}$ spectra.

nanometer distances. This is consistent with weak $\mathrm{H}$ bonds between the surface silanols and adsorbed olefins, similar to what has been proposed for olefin-methanol $\mathrm{H}$ bonds in solution. ${ }^{49}$ Indeed, $\pi$ - $\mathrm{H}$ bonds have recently been observed experimentally for olefins adsorbed on hydroxylated silica surfaces. ${ }^{50,51}$ The participation of surface Si-OH groups in olefin adsorption is confirmed by FTIR spectroscopy, which shows an increase in the intensity of broad signals from interacting $\mathrm{Si}-\mathrm{OH}$ groups as a function of reaction time, with concomitant decrease in intensity of the signal from isolated Si-OH groups (Fig. S35).

The 2D ${ }^{29} \mathrm{Si}\left\{{ }^{1} \mathrm{H}\right\}$ DNP-HETCOR spectra also corroborate the presence of coadsorbed dichlorobenzene molecules and trimethylsiloxy surface moieties. At longer ${ }^{1} \mathrm{H}-{ }^{29} \mathrm{Si}$ contact times (5 ms, Fig. 5b), additional correlated signals are detected at 1.8 and $8.1 \mathrm{ppm}$, which respectively arise from alkyl and aromatic ${ }^{1} \mathrm{H}$ species, consistent with the close proximity of the aliphatic chains of the long-chain olefins at the silica surface and the coadsorption of 1,2-dichlorobenzene molecules, respectively. Weak ${ }^{29} \mathrm{Si}$ signals are also detected at 28 and 22 ppm (Figure S39), which are assigned based on their chemical shift positions to two 
different types of surface - $\mathrm{OSi}\left(\mathrm{CH}_{3}\right)_{3}$ that are byproducts of the decomposition of the organosilicon reductants.

\section{Dynamics and adsorption of olefins on silica}

Overall, the solid-state NMR and FTIR results and analyses evidence that long-chain internal olefin metathesis products adsorb competitively with solvent molecules at surface Si-OH sites. Such substratesurface interactions have not previously been the subject of detailed analysis in the field of olefin metathesis, and indeed are unexpected for liquid phase catalysis with non-polar substrates in a polar solvent. However, it has been recognized previously that adsorption of olefins importantly influences activity and selectivity for gas-phase catalysis. For instance, strong adsorption of olefins on alumina favors secondary metathesis isomerization reactions in the $\mathrm{CH}_{3} \mathrm{ReO}_{3} / \mathrm{Al}_{2} \mathrm{O}_{3}$ system, leading to thermodynamic product selectivities for propene metathesis across a broad range of contact times. ${ }^{37,52}$ Modification of the alumina surface to passivate surface Al-OH moieties yields non-equilibrium E/Z selectivities. ${ }^{52}$ While alumina and silica-alumina materials are well known to strongly adsorb olefins, ${ }^{53}$ silica is typically considered a more inert support due to the absence of strong Brønsted or Lewis acid sites. However, there is growing recognition of the importance of surface interactions in mediating reactivity, particularly for challenging substrates. For instance, interactions of functionalized olefins containing ester groups and surface silanol groups were recently found to enrich the near-surface concentration of olefins and influence product selectivities for ring-closing metathesis reactions catalyzed by well-defined cationic Mo alkylidenes supported on mesoporous silicas. ${ }^{54}$ The silica-supported Mo oxo system is known to possess strong Brønsted acid sites that could act as adsorption sites, ${ }^{11,55}$ and even on bare hydroxylated silica the interaction energies of hydrocarbons are known to increase as a function of chain length and are greater for alkenes than alkanes. ${ }^{56}$ The catalytic reaction tests and spectroscopic analyses discussed above show that substratesilica interactions are non-negligible for long-chain olefinic hydrocarbons and indeed have significant effects on catalytic reaction properties at low reaction temperatures $\left(<100{ }^{\circ} \mathrm{C}\right)$.

To assess further the nature of the olefin-surface interactions, we contacted dehydroxylated silica $\mathrm{SiO}_{2-700}$ with 1-hexadecene and its metathesis product, 15-triacontene (see SI for details). IR and solid-state ${ }^{1} \mathrm{H}$ 


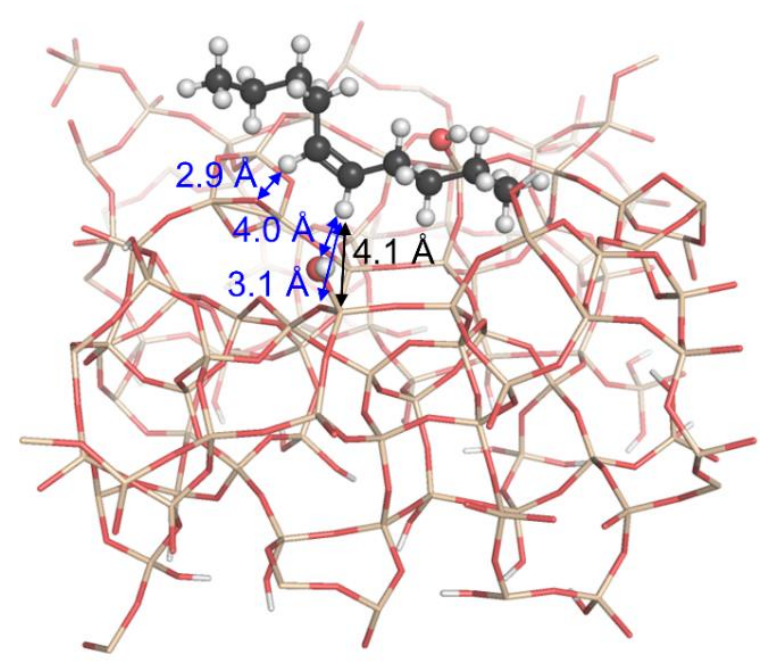

Figure 6. Representative conformation from MD simulations of an internal olefin (cis-5-decene) adsorbed on a model surface of dehydroxylated silica. The three shortest $\mathrm{CH}-\mathrm{O}$ distances are indicated with blue arrows, and the black arrow indicates an olefinic $\mathrm{CH}$ to $Q^{3} \mathrm{Si}$ distance consistent with the 2D solid-state ${ }^{29} \mathrm{Si}\left\{{ }^{1} \mathrm{H}\right\}$ DNP-HETCOR NMR spectrum in Figure 5a.

NMR spectra of the washed and dried materials (Fig. S40 and S41) show that both olefins adsorb appreciably on the bare silica surface, though the $\mathrm{C} 30$ metathesis product to a much greater extent, with concomitant perturbation of the IR signal from isolated Si-OH groups. To gain more insights into these effects, we conducted molecular dynamics (MD) calculations of internal and terminal linear olefins of varied chain lengths on a periodic surface model of dehydroxylated amorphous silica having approximately $1.1 \mathrm{OH} / \mathrm{nm}^{2}{ }^{27}$ In each case, the olefins appear to be stabilized on the surface by interactions with surface silanols, with the distances between surface $-\mathrm{OH}$ and olefinic carbon atoms ranging from 0.22 to $0.51 \mathrm{~nm}$ (Table S9), consistent with the solid-state NMR results discussed above. These distances are within the range expected for olefin- $\mathrm{OH}$ hydrogen bonding interactions. ${ }^{49}$ Short distances $(0.24$ to $0.36 \mathrm{~nm})$ are also observed between allylic and aliphatic $\mathrm{H}$ atoms and surface siloxane bridges, suggesting that dispersion interactions with surface siloxanes provide additional stabilization of the adsorbed olefins at the surface, increasing in strength as a function of chain length. Indeed, the magnitude of the calculated energies of adsorption generally increases as a function of chain length for both terminal and internal olefins (Table S9), with internal olefins exhibiting slightly stronger adsorption energies compared to terminal olefins of 
the same molecular weight. These trends are qualitatively consistent with measurements of olefin adsorption energies and enthalpies on silica by gas chromatography. ${ }^{56}$

Based on the spectroscopic and MD analyses, the stabilization of olefins at the surface of silica is due to van der Waals interactions between the olefins and surface $\mathrm{Si}-\mathrm{OH}$ and siloxane moieties; the increase in adsorption energy follows the olefin chain length and reflects the increasing contribution of dispersion forces. FTIR analyses of $(\equiv \mathbf{S i O})_{2} \mathbf{M o}(=\mathbf{O})_{2}$-red after reaction, as well as dehydroxylated silica devoid of Mo centers contacted with different olefins, corroborate that isolated Si-OH groups are primarily responsible for the observed olefin-surface interactions (Fig. S35 and S40). By comparison, $\mathbf{M o}^{+} / \mathrm{SiO}_{2}$ exhibits only broadened and displaced FTIR signals from $\mathrm{SiOH}$ species interacting with organic moieties, which are minimally perturbed on the post-reaction catalyst (Fig. S42), suggesting that they participate to a lesser extent in olefin adsorption. Indeed, no resolved ${ }^{1} \mathrm{H}$ NMR signals from adsorbed olefin are observed in the ${ }^{1} \mathrm{H}$ MAS NMR spectrum of $\mathbf{M o}^{+} / \mathbf{S i O}_{2}$ post-reaction, though since such signals would overlap in part with the ${ }^{1} \mathrm{H}$ signals from the organic ligands we cannot preclude the adsorption of olefins to some degree. Overall, these observations suggest that the adsorption of bulky di-substituted and consequently more electron rich olefin metathesis products on the catalyst surface, to which we attribute the decreasing activity with substrate chain length of $(=\mathbf{S i O})_{2} \mathbf{M o}(=\mathbf{O})_{2}$-red, depends primarily on the quantities and types of Si-OH groups.

\section{Conclusions}

Silica-supported Mo-based catalysts are active and selective for low-temperature $\left(<100{ }^{\circ} \mathrm{C}\right)$ metathesis of linear $\alpha$-olefins in the liquid phase, with reaction properties that depend strongly on the characteristics of both catalyst and substrate, decreasing sharply as a function of olefin chain length for supported Mo oxo based catalysts. By comparison, the molecularly defined alkylidene catalysts whether homogeneous or silica-supported display high reaction rates $\left(>250 \mathrm{~min}^{-1}\right)$ with much less dependence on olefin chain length. FTIR and solid-state NMR analyses of catalysts post-metathesis show that the internal olefin metathesis products adsorb on the catalyst support via interactions of olefinic moieties and surface $(\mathrm{OH})$ 
functionalities; this correlates with the decreased catalyst activity. The observations are further corroborated by MD calculations. Overall, the analyses indicate that the metathesis rate of long-chain linear liquid $\alpha$-olefins can be limited by desorption of the bulky internal olefin products from the solid catalyst even in the condensed phase for metathesis catalysts based on supported Mo oxides, prepared via SOMC or classical wet impregnation approaches. This study also shows the utility of sensitivity-enhanced solid-state NMR as a tool for elucidating surface interactions in heterogeneous systems and understanding the molecular-scale origins of catalytic reaction properties. Besides offering insights into the origins of the lower activity for supported catalysts based on metal oxides, our study highlights the advantages of molecularly defined supported catalysts prepared via SOMC that display very high metathesis activity due, in part, to the ease of product desorption. The identification of strong surface-substrate interactions that influence reactivity is particularly significant in the context of ongoing efforts to expand the scope of heterogeneous catalysis, for instance to upgrading of biomass feedstocks, which are often bulky and oxygenated molecules. $^{58,59}$

\section{Supporting Information}

Experimental section, catalyst characterization, catalytic reaction data, additional solid-state NMR and FTIR analyses, summary of MD results.

\section{Author Contributions}

Z.J.B, G.P., G.J.S., and C.C. conceptualized the study, designed the methodology, and analyzed the results. Z.J.B. and S.L.S. synthesized the heterogeneous catalysts and conducted the reactivity tests. M.J.B. and M.R.B. developed and synthesized the molecular alkylidene catalyst. M.B. conducted the MD simulations. Z.J.B. and C.C. co-wrote the manuscript. All authors discussed the results and commented on the manuscript during its preparation. 


\section{Acknowledgements}

This work was supported by BP plc. Z.J.B. gratefully acknowledges financial support from the Swiss National Science Foundation, Spark award CRSK-2_190322. M.B. would like to thank the ETH Zurich Grant program (ETH-44 18-1). M.R.B. acknowledges funding from the Deutsche Forschungsgemeinschaft (DFG; German Research Foundation, project number 358283783 - CRC 1333).

\section{References}

(1) Grubbs, R. H. Olefin-Metathesis Catalysts for the Preparation of Molecules and Materials (Nobel Lecture). Angew. Chemie - Int. Ed. 2006, 45 (23), 3760-3765.

(2) Schrock, R. R.; Hoveyda, A. H. Molybdenum and Tungsten Imido Alkylidene Complexes as Efficient Olefin-Metathesis Catalysts. Angew. Chemie - Int. Ed. 2003, 42 (38), 4592-4633.

(3) Buchmeiser, M. R.; Sen, S.; Unold, J.; Frey, W. N-Heterocyclic Carbene, High Oxidation State Molybdenum Alkylidene Complexes: Functional-Group-Tolerant Cationic Metathesis Catalysts. Angew. Chemie - Int. Ed. 2014, 53 (35), 9384-9388.

(4) Koh, M. J.; Nguyen, T. T.; Lam, J. K.; Torker, S.; Hyvl, J.; Schrock, R. R.; Hoveyda, A. H. Molybdenum Chloride Catalysts for Z-Selective Olefin Metathesis Reactions. Nature 2017, 542 (7639), 80-85.

(5) Nguyen, T. T.; Koh, M. J.; Mann, T. J.; Schrock, R. R.; Hoveyda, A. H. Synthesis of E- and ZTrisubstituted Alkenes by Catalytic Cross-Metathesis. Nature 2017, 552 (7685), 347-354.

(6) Ogba, O. M.; Warner, N. C.; O’Leary, D. J.; Grubbs, R. H. Recent Advances in Ruthenium-Based Olefin Metathesis. Chem. Soc. Rev. 2018, 47 (12), 4510-4544.

(7) Mol, J. C. Industrial Applications of Olefin Metathesis. J. Mol. Catal. A Chem. 2004, 213 (1), 3945.

(8) Lwin, S.; Wachs, I. E. Olefin Metathesis by Supported Metal Oxide Catalysts. ACS Catal. 2014, $4(8), 2505-2520$. 
Generation of Active Sites in Olefin Metathesis. J. Am. Chem. Soc. 2012, 134 (28), 11462-11473.

(10) Chan, K. W.; Mance, D.; Safonova, O. V.; Copéret, C. Well-Defined Silica-Supported Tungsten(IV)-Oxo Complex: Olefin Metathesis Activity, Initiation, and Role of Brønsted Acid Sites. $J$. Am. Chem. Soc. 2019, 141 (45), 18286-18292.

(11) Gani, T. Z. H.; Berkson, Z. J.; Zhu, R.; Kang, J. H.; Iorio, J. R. Di; Chan, W.; Consoli, D. F.; Shaikh, S. K.; Copéret, C.; Román-, Y. Universal Promotion of Heterogeneous Olefin Metathesis Catalysts by Controlling Dynamic Active Site Renewal. https://doi.org/10.33774/chemrxiv-2021-140tk. (12) Copéret, C.; Allouche, F.; Chan, K. W.; Conley, M. P.; Delley, M. F.; Fedorov, A.; Moroz, I. B.; Mougel, V.; Pucino, M.; Searles, K.; et al. Bridging the Gap between Industrial and Well-Defined Supported Catalysts. Angew. Chemie - Int. Ed. 2018, 57 (22), 6398-6440.

(13) Copéret, C.; Berkson, Z. J.; Chan, K. W.; de Jesus Silva, J.; Gordon, C. P.; Pucino, M.; Zhizhko, P. A. Olefin Metathesis: What Have We Learned about Homogeneous and Heterogeneous Catalysts from Surface Organometallic Chemistry? Chem. Sci. 2021, 12 (9), 3092-3115.

(14) Mougel, V.; Chan, K. W.; Siddiqi, G.; Kawakita, K.; Nagae, H.; Tsurugi, H.; Mashima, K.; Safonova, O.; Copéret, C. Low Temperature Activation of Supported Metathesis Catalysts by Organosilicon Reducing Agents. ACS Cent. Sci. 2016, 2 (8), 569-576.

(15) Yamamoto, K.; Chan, K. W.; Mougel, V.; Nagae, H.; Tsurugi, H.; Safonova, O. V.; Mashima, K.; Copéret, C. Silica-Supported Isolated Molybdenum Di-Oxo Species: Formation and Activation with Organosilicon Agent for Olefin Metathesis. Chem. Commun. 2018, 54 (32), 3989-3992.

(16) Wolczanski, P. T. Chemistry of Electrophilic Metal Centres Coordinated by Silox (TBu3SiO), Tritox (TBu3CO) and Related Binfunctional Ligands. Polyhedron 1995, 14 (22), 3335-3362.

(17) Rendón, N.; Berthoud, R.; Blanc, F.; Gajan, D.; Maishal, T.; Basset, J. M.; Copéret, C.; Lesage, A.; Emsley, L.; Marinescu, S. C.; et al. Well-Defined Silica-Supported Mo-Alkylidene Catalyst Precursors Containing One OR Substituent: Methods of Preparation and Structure-Reactivity Relationship in Alkene Metathesis. Chem. - A Eur. J. 2009, 15 (20), 5083-5089. 
Pucino, M.; Liao, W. C.; Chan, K. W.; Lam, E.; Schowner, R.; Zhizhko, P. A.; Buchmeiser, M.

R.; Copéret, C. Metal-Surface Interactions and Surface Heterogeneity in 'Well-Defined' Silica-Supported Alkene Metathesis Catalysts: Evidences and Consequences. Helv. Chim. Acta 2020, 103 (6).

(19) Sydora, O. L. Selective Ethylene Oligomerization. Organometallics 2019, 38 (5), 997-1010.

(20) Keim, W. Oligomerization of Ethylene to $\alpha$-Olefins: Discovery and Development of the Shell Higher Olefin Process (SHOP). Angew. Chemie - Int. Ed. 2013, 52 (48), 12492-12496.

(21) Rofer-DePoorter, C. K. A Comprehensive Mechanism for the Fischer-Tropsch Synthesis. Chem. Rev. 1981, 81 (5), 447-474.

(22) Stenger, H. G.; Satterfleld, C. N. Effect of Liquid Composition on the Slurry Fischer-Tropsch Synthesis. 2. Product Selectivity. Ind. Eng. Chem. Process Des. Dev. 1985, 24 (2), 411-415.

(23) Ishii, Y.; Yesinowski, J. P.; Tycko, R. Sensitivity Enhancement in Solid-State 13C NMR of Synthetic Polymers and Biopolymers by 1H NMR Detection with High-Speed Magic Angle Spinning. $J$. Am. Chem. Soc. 2001, 123 (12), 2921-2922.

(24) Venkatesh, A.; Hanrahan, M. P.; Rossini, A. J. Proton Detection of MAS Solid-State NMR Spectra of Half-Integer Quadrupolar Nuclei. Solid State Nucl. Magn. Reson. 2017, 84 (January), 171-181.

(25) Rossini, A. J.; Zagdoun, A.; Lelli, M.; Lesage, A.; Copéret, C.; Emsley, L. Dynamic Nuclear Polarization Surface Enhanced NMR Spectroscopy. Acc. Chem. Res. 2013, 46 (9), 1942-1951.

(26) Lelli, M.; Chaudhari, S. R.; Gajan, D.; Casano, G.; Rossini, A. J.; Ouari, O.; Tordo, P.; Lesage, A.; Emsley, L. Solid-State Dynamic Nuclear Polarization at 9.4 and $18.8 \mathrm{~T}$ from $100 \mathrm{~K}$ to Room Temperature. J. Am. Chem. Soc. 2015, 137 (46), 14558-14561.

(27) Finiels, A.; Fajula, F.; Hulea, V. Nickel-Based Solid Catalysts for Ethylene Oligomerization-a Review. Catal. Sci. Technol. 2014, 4 (8), 2412-2426.

(28) Britovsek, G. J. P.; Malinowski, R.; McGuinness, D. S.; Nobbs, J. D.; Tomov, A. K.; Wadsley, A. W.; Young, C. T. Ethylene Oligomerization beyond Schulz-Flory Distributions. ACS Catal. 2015, 5 (11), $6922-6925$. 
the Fischer-Tropsch Synthesis. Energy and Fuels 1988, 2 (6), 734-739.

(30) Zhizhko, P. A.; Mougel, V.; De Jesus Silva, J.; Copéret, C. Benchmarked Intrinsic Olefin Metathesis Activity: Mo vs. W. Helv. Chim. Acta 2018, 101 (3), 2-7.

(31) Zhizhko, P. A.; Toth, F.; Gordon, C. P.; Chan, K. W.; Liao, W. C.; Mougel, V.; Copéret, C. Molecular and Silica-Supported Mo and W D0 Imido-Methoxybenzylidene Complexes: Structure and Metathesis Activity. Helv. Chim. Acta 2019, 102 (10), 1-11.

(32) Poater, A.; Solans-Monfort, X.; Clot, E.; Copéret, C.; Eisenstein, O. Understanding D0-Olefin Metathesis Catalysts: Which Metal, Which Ligands? J. Am. Chem. Soc. 2007, 129 (26), 8207-8216.

(33) Saito, T.; Nishiyama, H.; Tanahashi, H.; Kawakita, K.; Tsurugi, H.; Mashima, K. 1,4Bis(Trimethylsilyl)-1,4-Diaza-2,5-Cyclohexadienes as Strong Salt-Free Reductants for Generating LowValent Early Transition Metals with Electron-Donating Ligands. J. Am. Chem. Soc. 2014, 136(13), 51615170.

(34) Lee, E. L.; Wachs, I. E. In Situ Spectroscopic Investigation of the Molecular and Electronic Structures of SiO 2 Supported Surface Metal Oxides. J. Phys. Chem. C 2007, 111 (39), 14410-14425.

(35) Chempath, S.; Yihua, Z.; Bell, A. T. DFT Studies of the Structure and Vibrational Spectra of Isolated Molybdena Species Supported on Silica. J. Phys. Chem. C 2007, 111 (3), 1291-1298.

(36) Crabtree, R. H. The Organometallic Chemistry of the Transition Metals, 6th Ed.; Hoboken, NJ, 2014.

(37) Copéret, C. Stereoselectivity of Supported Alkene Metathesis Catalysts: A Goal and a Tool to Characterize Active Sites. Beilstein J. Org. Chem. 2011, 7, 13-21.

(38) Buchmeiser, M. R.; Sen, S.; Lienert, C.; Widmann, L.; Schowner, R.; Herz, K.; Hauser, P.; Frey, W.; Wang, D. Molybdenum Imido Alkylidene N-Heterocyclic Carbene Complexes: StructureProductivity Correlations and Mechanistic Insights. ChemCatChem 2016, 8 (16), 2710-2723.

(39) Pucino, M.; Inoue, M.; Gordon, C. P.; Schowner, R.; Stöhr, L.; Sen, S.; Hegedüs, C.; Robé, E.; Tóth, F.; Buchmeiser, M. R.; et al. Promoting Terminal Olefin Metathesis with a Supported Cationic 
Molybdenum Imido Alkylidene N-Heterocyclic Carbene Catalyst. Angew. Chemie - Int. Ed. 2018, 57 (44), 14566-14569.

(40) Cadars, S.; Mifsud, N.; Lesage, A.; Epping, J. D.; Hedin, N.; Chmelka, B. F.; Emsley, L. Dynamics and Disorder in Surfactant-Templated Silicate Layers Studied by Solid-State NMR Dephasing Times and Correlated Line Shapes. J. Phys. Chem. C 2008, 112 (25), 9145-9154.

(41) Kobayashi, T.; Perras, F. A.; Slowing, I. I.; Sadow, A. D.; Pruski, M. Dynamic Nuclear Polarization Solid-State NMR in Heterogeneous Catalysis Research. ACS Catal. 2015, 5 (12), 7055-7062. (42) Gutmann, T.; Groszewicz, P. B.; Buntkowsky, G. Solid-State NMR of Nanocrystals, 1st ed.; Elsevier Ltd., 2019; Vol. 97.

(43) Hanrahan, M. P.; Chen, Y.; Blome-Fernández, R.; Stein, J. L.; Pach, G. F.; Adamson, M. A. S. S.; Neale, N. R.; Cossairt, B. M.; Vela, J.; Rossini, A. J. Probing the Surface Structure of Semiconductor Nanoparticles by DNP SENS with Dielectric Support Materials. J. Am. Chem. Soc. 2019, 141 (39), 1553215546.

(44) Perras, F. A.; Padmos, J. D.; Johnson, R. L.; Wang, L.-L. L.; Schwartz, T. J.; Kobayashi, T.; Horton, J. H.; Dumesic, J. A.; Shanks, B. H.; Johnson, D. D.; et al. Characterizing Substrate-Surface Interactions on Alumina-Supported Metal Catalysts by Dynamic Nuclear Polarization-Enhanced DoubleResonance NMR Spectroscopy. J. Am. Chem. Soc. 2017, 139 (7), 2702-2709.

(45) Rankin, A. G. M. M.; Webb, P. B.; Dawson, D. M.; Viger-gravel, J.; Walder, B. J.; Emsley, L.; Ashbrook, S. E. Determining the Surface Structure of Silicated Alumina Catalysts via Isotopic Enrichment and Dynamic Nuclear Polarization Surface-Enhanced NMR Spectroscopy. J. Phys. Chem. C 2017, 121 (41), 22977-22984.

(46) Sangodkar, R. P.; Smith, B. J.; Gajan, D.; Rossini, A. J.; Roberts, L. R.; Funkhouser, G. P.; Lesage, A.; Emsley, L.; Chmelka, B. F. Influences of Dilute Organic Adsorbates on the Hydration of LowSurface-Area Silicates. J. Am. Chem. Soc. 2015, 137 (25), 8096-8112.

(47) Valla, M.; Rossini, A. J.; Caillot, M.; Chizallet, C.; Raybaud, P.; Digne, M.; Chaumonnot, A.; Lesage, A.; Emsley, L.; Van Bokhoven, J. A.; et al. Atomic Description of the Interface between Silica 
and Alumina in Aluminosilicates through Dynamic Nuclear Polarization Surface-Enhanced NMR Spectroscopy and First-Principles Calculations. J. Am. Chem. Soc. 2015, 137 (33), 10710-10719.

(48) Smeets, S.; Berkson, Z. J.; Xie, D.; Zones, S. I.; Wan, W.; Zou, X.; Hsieh, M. F.; Chmelka, B. F.; McCusker, L. B.; Baerlocher, C. Well-Defined Silanols in the Structure of the Calcined High-Silica Zeolite SSZ-70: New Understanding of a Successful Catalytic Material. J. Am. Chem. Soc. 2017, 139 (46), 16803-16812.

(49) Zhang, Z.; Xiao, T.; Al-Megren, H.; Aldrees, S. A.; Al-Kinany, M.; Kuznetsov, V. L.; Kuznetsov, M. L.; Edwards, P. P. Hydrogen Bonds between Methanol and the Light Liquid Olefins 1-Pentene and 1Hexene: From Application to Fundamental Science. Chem. Commun. 2017, 53 (28), 4026-4029.

(50) Fang, Y.; Riahi, S.; McDonald, A. T.; Shrestha, M.; Tobias, D. J.; Grassian, V. H. What Is the Driving Force behind the Adsorption of Hydrophobic Molecules on Hydrophilic Surfaces? J. Phys. Chem. Lett. 2019, 10 (3), 468-473.

(51) Frank, E. S.; Fan, H.; Shrestha, M.; Riahi, S.; Tobias, D. J.; Grassian, V. H. Impact of Adsorbed Water on the Interaction of Limonene with Hydroxylated SiO2: Implications of $\pi$-Hydrogen Bonding for Surfaces in Humid Environments. J. Phys. Chem. A 2020, 124 (50), 10592-10599.

(52) Salameh, A.; Baudouin, A.; Basset, J. M.; Copéret, C. Tuning the Selectivity of AluminaSupported (CH3)ReO3 by Modifying the Surface Properties of the Support. Angew. Chemie - Int. Ed. 2008, 47 (11), 2117-2120.

(53) Maciver, D. S.; Zabor, R. C.; Emmett, P. H. The Adsorption of Normal Olefins on Silica-Alumina Catalysts. J. Phys. Chem. 1959, 63 (4), 484-489.

(54) Ziegler, F.; Kraus, H.; Benedikter, M. J.; Wang, D.; Bruckner, J. R.; Nowakowski, M.; Weißer, K.; Solodenko, H.; Schmitz, G.; Bauer, M.; et al. Confinement Effects for Efficient Macrocyclization Reactions with Supported Cationic Molybdenum Imido Alkylidene N-Heterocyclic Carbene Complexes. ACS Catal. 2021, 11570-11578. 

(August), 110580.

(56) Wang, M.-J.; Wolff, S.; Donnet, J.-B. Filler-Elastomer Interactions. Part I: Silica Surface Energies and Interactions with Model Compounds. Rubber Chem. Technol. 1991, 64 (4), 559-576.

(57) Comas-Vives, A. Amorphous SiO2 Surface Models: Energetics of the Dehydroxylation Process, Strain, Ab Initio Atomistic Thermodynamics and IR Spectroscopic Signatures. Phys. Chem. Chem. Phys. 2016, $18,7475-7482$

(58) Stöcker, M. Biofuels and Biomass-to-Liquid Fuels in the Biorefinery: Catalytic Conversion of Lignocellulosic Biomass Using Porous Materials. Angew. Chemie - Int. Ed. 2008, 47 (48), 9200-9211. (59) Sudarsanam, P.; Peeters, E.; Makshina, E. V.; Parvulescu, V. I.; Sels, B. F. Advances in Porous and Nanoscale Catalysts for Viable Biomass Conversion. Chem. Soc. Rev. 2019, 48 (8), 2366-2421. 